La educación en el Chad

\title{
¿Un punto de inflexión en el corazón de África?
}

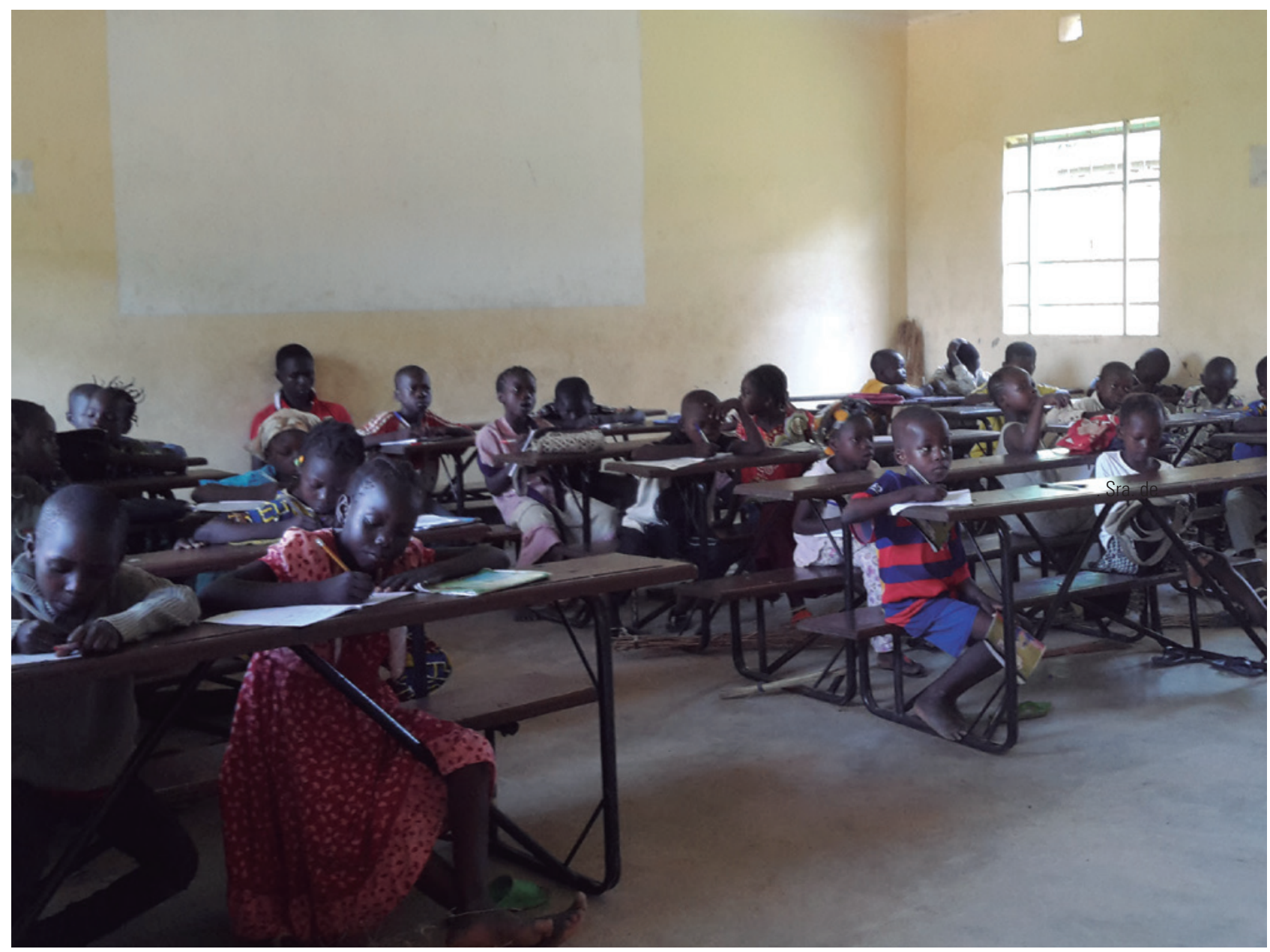

En ocasiones, es necesario salir de la zona de confort para recordar lo grande y diverso que es nuestro planeta. Cuando se viaja a un país como el Chad con el ánimo de conocerlo y amarlo, se encuentran diversas dicotomías

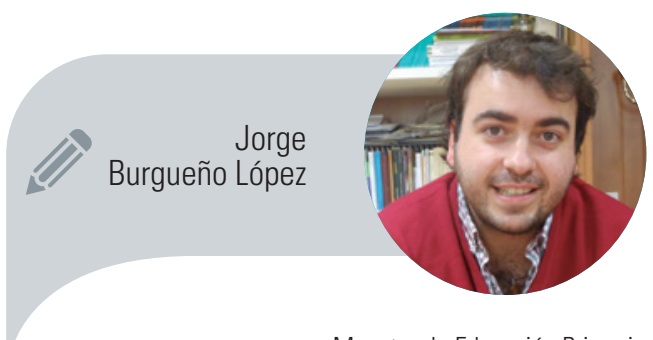
que merecen un periodo de reflexión posterior. La educación se presenta como un pilar fundamental para que el desarrollo de una sociedad se pueda llevar a cabo. 


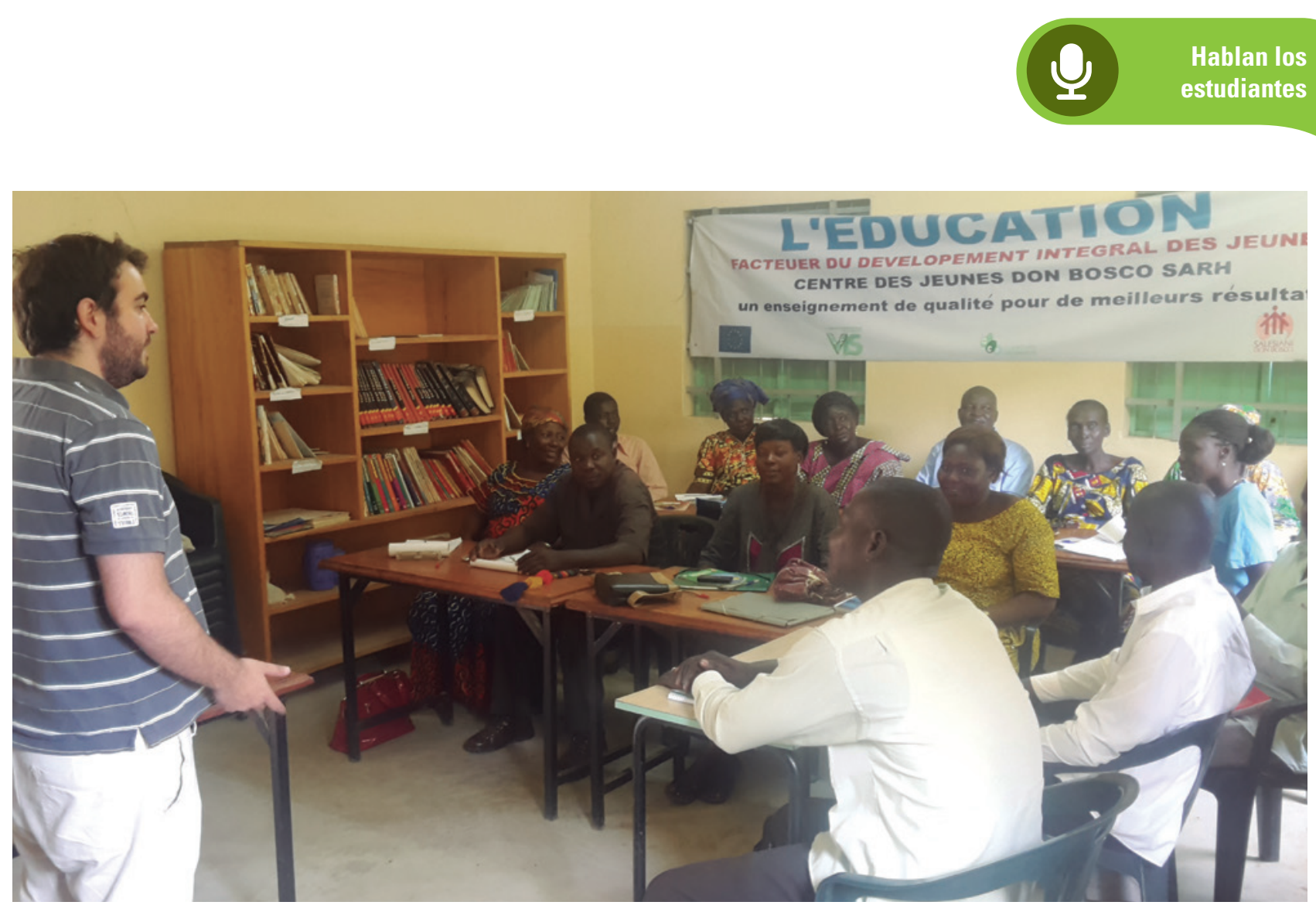

Un buen día un niño llegó a una playa y observó que había millones de estrellas de mar sobre la arena que habían sido depositadas por el mar. Enseguida al niño lo invadió una inmensa tristeza cuando se dio cuenta de que la marea estaba bajando y que, para cuando subiera, estarían todas muertas. Sin pensarlo se puso a cogerlas desesperadamente una a una y a lanzarlas al mar. Corría desenfrenado. Parecía no tener consuelo. Un señor mayor que estaba cerca observó lo que el niño hacía y le espetó en tono jocoso:

“¿Pero qué estás haciendo? ¿Cómo puedes ser tan iluso? Hay millones de estrellas. No vas a poder salvarlas a todas. No te das cuenta de que tu esfuerzo no vale la pena". El niño lo observó con mirada seria, se agachó, sostuvo otra estrella de mar con dos dedos, la alzó, la lanzó al mar y, clavando de nuevo la mirada en sus ojos, le dijo aleccionándolo:

"A esa sí le valió la pena".

\section{Corazón inquieto}

El mundo es inabarcable, demasiado diverso. Existen tantas culturas, idiomas, tradiciones y etnias que pretender conocerlas todas es misión imposible. Sin embargo, cada rincón del planeta que voy conociendo abre mi mente y encuentra un lugar privilegiado en mi corazón.

Por ello, decidí embarcarme en el proyecto de inmersión cultural que lleva a cabo desde hace trece años la asociación de los jesuitas EnxarTxad, con el objetivo principal de conocer, comprender y amar un país situado en el centro del continente africano: Chad.
Una nación que destaca por sus contrastes: cristianos y musulmanes, desierto y vegetación frondosa, hostilidad militar y acogida radical... Con apenas medio siglo de independencia colonial, el Chad avanza lentamente en su torpe intento por abrirse hueco entre las antiguas colonias francesas del África occidental. La inestabilidad y corrupción política, los bajos precios del petróleo (principal materia prima de exportación del país) o la delgada línea que separa la religión de la tradición en la cultura chadiana, son algunos de los motivos que dificultan el crecimiento y el desarrollo del país. Todo ello, por supuesto, con el beneplácito de los estados europeos, que influyen activa o pasivamente en esta estructura desigual con el objetivo de favorecer sus propios intereses.

Esta es parte de una realidad compleja y extensa que, prácticamente sin pedir permiso, sacudió los esquemas que previamente tenía establecidos sobre la humanidad.

Y, aunque vivido de forma intensa y profunda, no he hecho más que arañar la superficie de una verdad que, aún hoy, hace necesaria la reflexión e investigación sobre la posibilidad de una sociedad más igualitaria y menos injusta.

Es curioso, sin embargo, cómo, tras las consideraciones y las cavilaciones filosóficas y sociales acerca de la voluntad del ser humano, después de la indignación, 

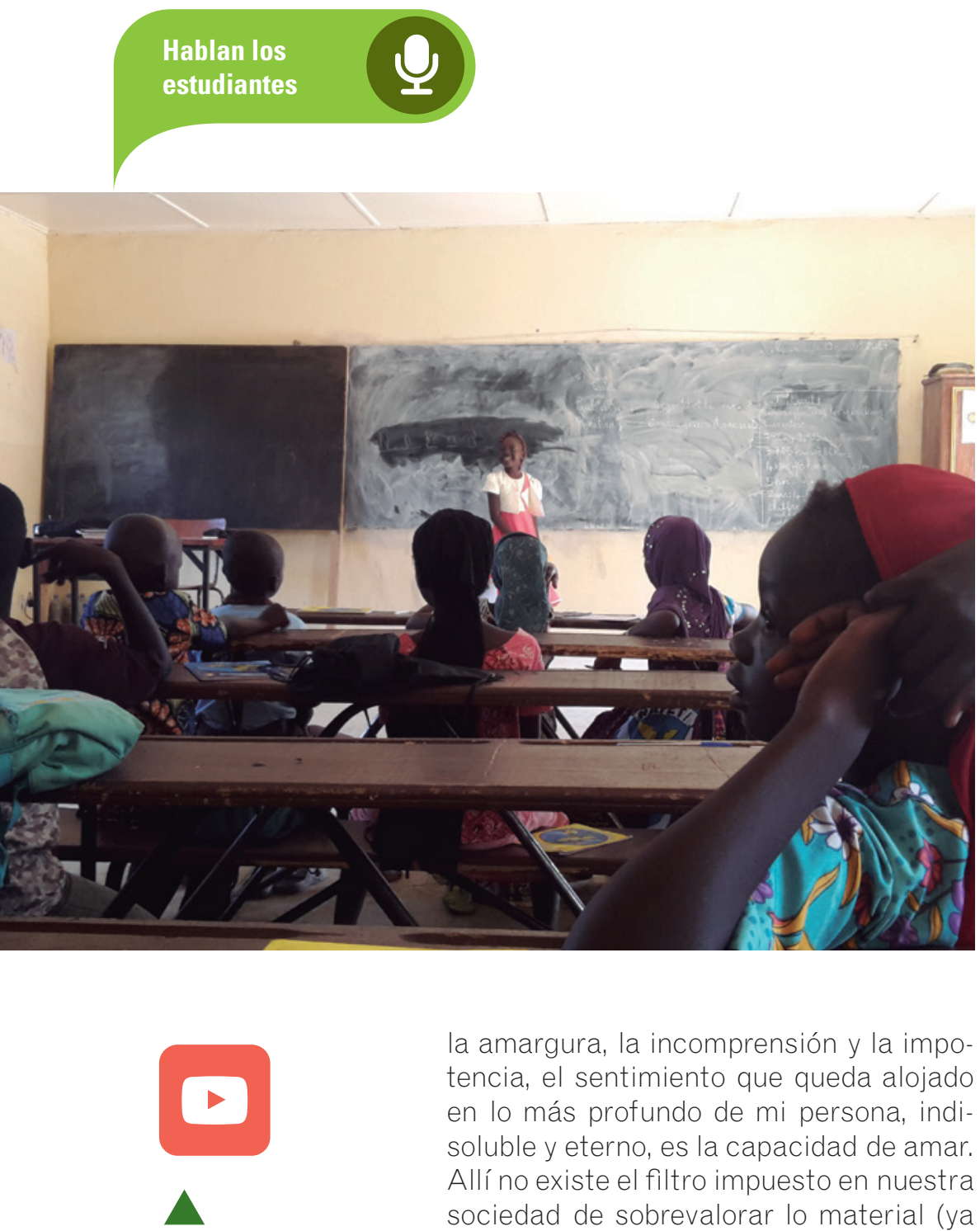

Clase en Chad la amargura, la incomprensión y la impotencia, el sentimiento que queda alojado en lo más profundo de mi persona, indisoluble y eterno, es la capacidad de amar. Allí no existe el filtro impuesto en nuestra sociedad de sobrevalorar lo material (ya que apenas hay objetos de valor), por lo que las relaciones personales son más intensas, más sinceras, más cercanas. En el momento en el que se nos dio la oportunidad de conocer en profundidad a personas concretas, surgió la inevitable situación de generar un vínculo basado en el cariño, tal y como le indica el zorro de El Principito de Saint-Exupéry al pequeño personaje: "Sólo se conocen bien las cosas que se domestican". Es decir, que sólo se puede amar lo que se conoce.

Con esta actitud nos adentramos en una realidad desconocida, en ocasiones abierta y dispuesta a mostrarse y en otras, hostil, revelando la existencia de juicios previos hacia lo extraño.

\section{La educación, pilar fundamental}

La inmersión se centró en los pilares principales para el progreso de una sociedad: sanidad y educación. Éstos estarían sin embargo incompletos si no incluyéramos un tercer pilar fundamental y transversal de toda la experiencia: la solidaridad. El trabajo con los más pobres, con los más necesitados, fue clave para ese acercamiento y esa comprensión evocados en El
Principito: las actividades con los niños de la calle, expulsados o escapados de casa, luchando por sobrevivir cada día en los callejones de los alrededores del mercado, y los juegos con los niños malnutridos acogidos por las Misioneras de la Caridad de la Madre Teresa de Calcuta se convertirían en el contacto más directo con personas cuya misión diaria se basaba en la ayuda al prójimo más pequeño y débil.

En cuanto a la sanidad, no puedo más que expresar lo que mis compañeros estudiantes de medicina presenciaron en los hospitales: desnutrición, malaria, infecciones... Aunque lo más significativo e impactante era la falta de personal y material. En el hospital privado de la ciudad donde colaborábamos había tan sólo un médico que ni siquiera había podido realizar su especialidad. El resto eran enfermeras.

Los primeros jesuitas misioneros en este país, grandes visionarios, comprendieron la enorme necesidad de este frágil pilar y comenzaron con un proyecto en un pueblo del sur, Goundi, donde se creó un hospital que fuera referencia para varios centros de salud que se fueron construyendo en los pueblos de alrededor, donde se atendían los casos menos graves.

Y, por último, aquel que personalmente considero de mayor importancia para el desarrollo de una sociedad: la educación. No es difícil coincidir con el expresidente sudafricano Nelson Mandela cuando afirmaba categóricamente: "La educación es el arma más poderosa para cambiar el mundo". Sin duda él contribuyó al cambio y al progreso de una nación rota y dividida por el apartheid.

La educación en un país como el Chad no permite su crecimiento ni su desarrollo. La formación del profesorado, en los casos en los que se da, suele ser de un año de duración y en los ambientes rurales se selecciona a un alumno que ni siquiera ha terminado la Educación Secundaria para que se encargue de educar a los niños de los pueblos vecinos por una exigua remuneración económica. Una de las primeras actividades demandadas por el director del colegio de los salesianos al que acudíamos para dar clase de español a los niños, fue 


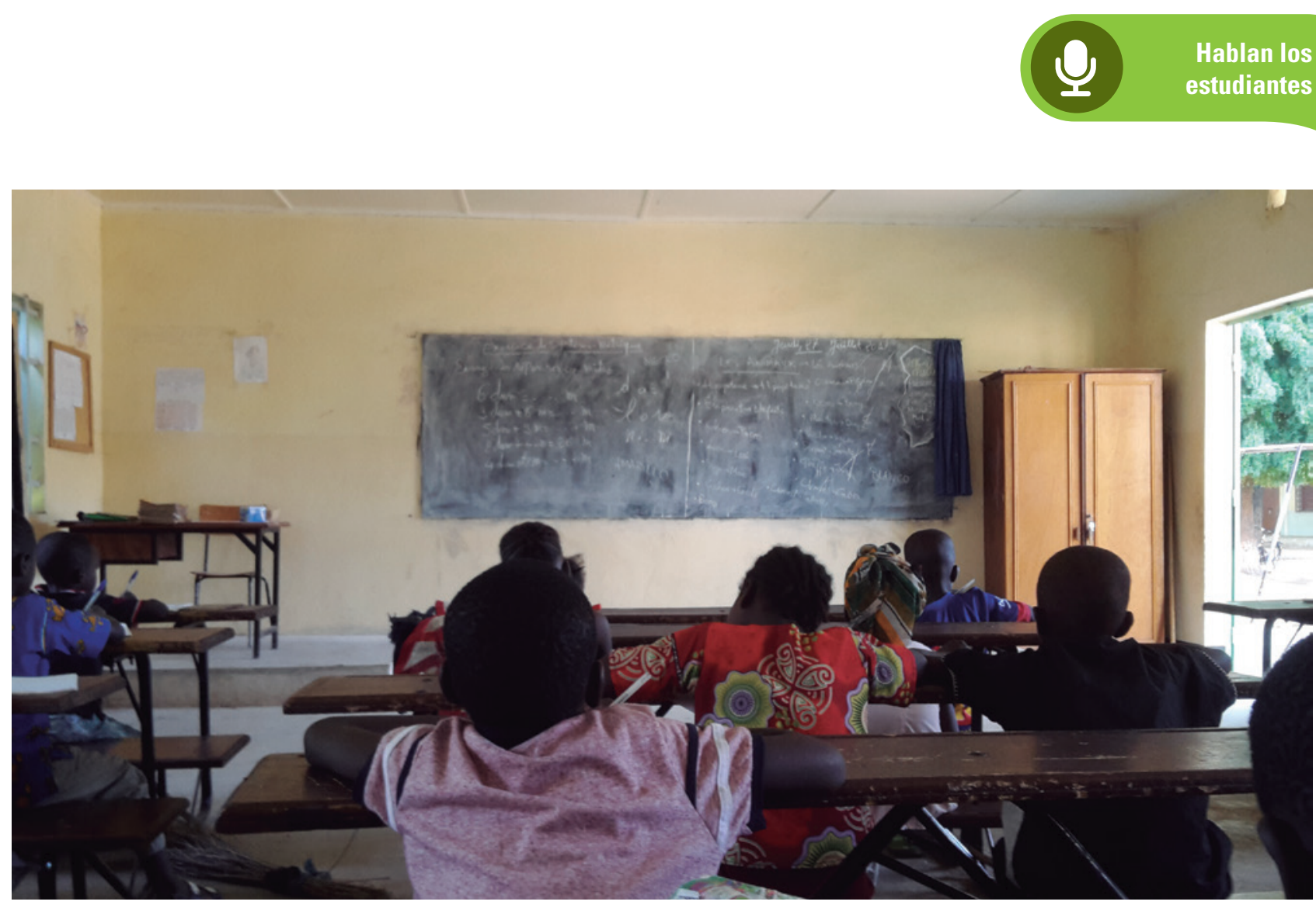

la posibilidad de impartir una formación de dos horas a profesores chadianos, ya que se encontraban en un curso de varios días y querían incluir una sesión presentada por mí. "¿Una formación sobre qué?", pregunté en un francés cada día más africanizado, "iSobre lo que sea!", me respondió el director, gesticulando vehementemente y con una sonrisa de oreja a oreja. "¿Tú sabes lo importante que es para ellos escuchar a un maestro en activo de España?" La verdad es que en ese momento no lo sabía. ¿Qué iba yo a enseñar a un grupo de profesores, padres y madres de familia, que Ilevaban en activo más del doble de años que yo? ¿Técnicas innovadoras? ¿Métodos de enseñanza? Finalmente opté por contarles lo que hacía yo en el aula en mi país y que se llevaran a sus aulas dos ideas fundamentales: la importancia de cuidar la relación con los alumnos y que amaran su profesión. Si acogieron algunas de mis palabras y las pusieron en práctica sólo Dios lo sabe.

Y tras esta formación, como ya he comentado, nuestra principal labor fue impartir clases de español a los alumnos de este colegio de Primaria: Saint Dominique Savio. Lo primero que llama la atención al entrar en un aula del centro no son sus pizarras carcomidas por la humedad, ni la ausencia de luz eléctrica, sino las decenas de brillantes ojos mirándome con estupefacción. Esta sorpresa no les impide
Lo primero que llama la atención al entrar en un aula del centro no son sus pizarras carcomidas por la humedad, ni la ausencia de luz eléctrica, sino las decenas de brillantes ojos mirándome con estupefacción

levantarse al unísono y saludar, como signo de respeto al profesor y adulto. Y después de un primer contacto de silencio y vacilaciones, mezcla de la timidez y el desconcierto por encontrarse con un europeo en el aula, comienzo a escuchar los chasquidos de los dedos de las manos alzadas respondiendo a las cuestiones que les iba planteando, precedido de otro gesto que me pareció solemne: cada vez que elegía un alumno para que respondiera, éste se levantaba para tomar la palabra.

La mezcla entre dignidad y sencillez en las aulas era sobrecogedora y un reflejo excelente de la cultura chadiana.

Los centros educativos religiosos no tienen conciertos con el gobierno, y la mayoría pasan por unas dificultades económicas tales que sufren para pagar incluso el sueldo de los maestros.

Gran cantidad de alumnos pasan de curso sin superar los contenidos mínimos 


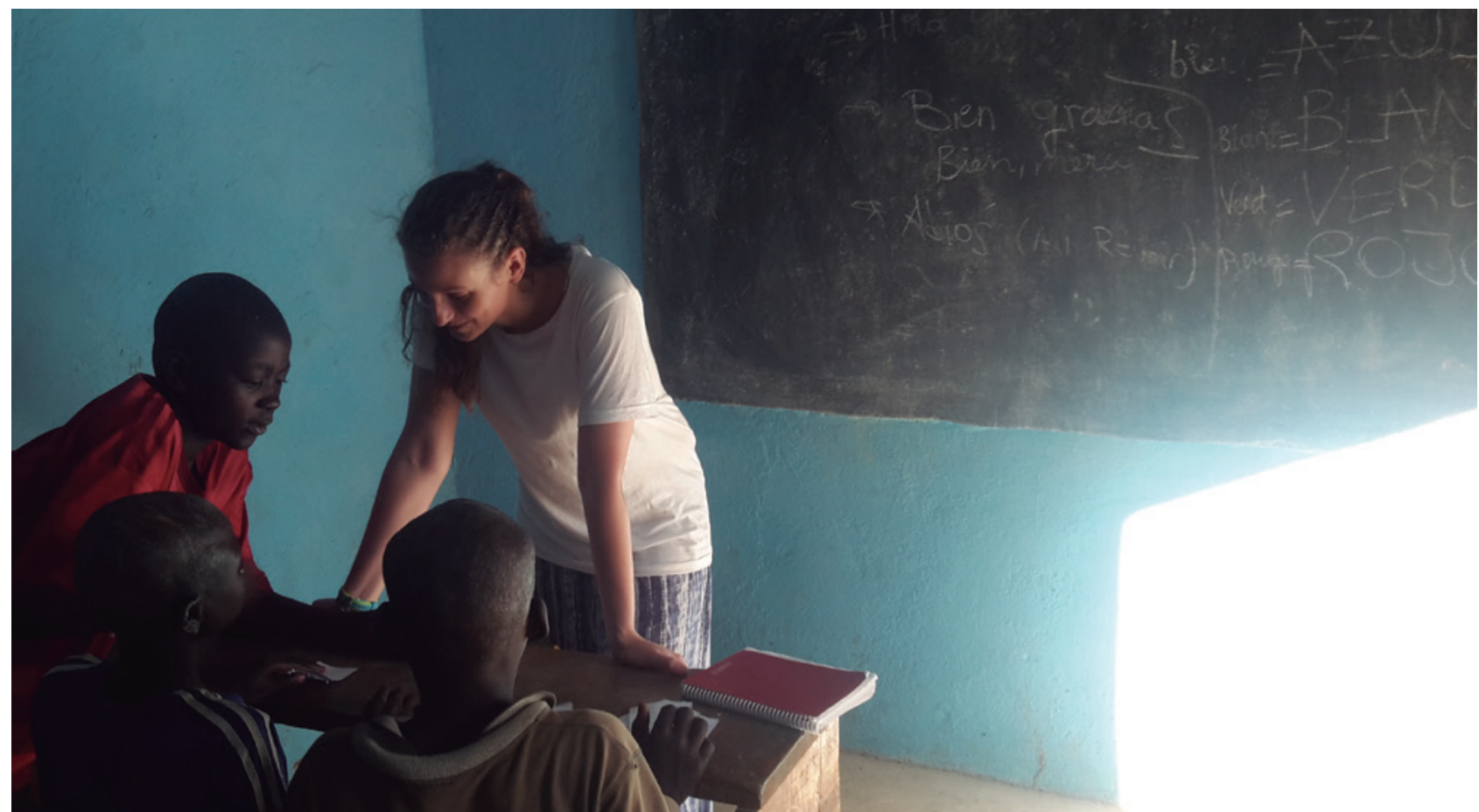

\section{Apostar por la educación significa diseñar un}

\section{plan sensato de formación de docentes, crear}

\section{estructuras físicas estables y valorar las labores}

\section{de mantenimiento}

al mundo..., en definitiva, ser consciente de que la base del crecimiento se encuentra en este pilar.

Sin embargo, a pesar de todo, hay pequeños oasis en este desierto educativo, que se hacen grandes en un país en el que las oportunidades hay que pelearlas. Fue en una de las tardes que teníamos reservadas para encuentros y reflexiones, donde conocimos a Elsa, una luchadora que representaba al mismo tiempo la ternura y la dignidad. Una figura que tuvo que hacer frente a la imagen que se tiene de la mujer ${ }^{1}$, que se esforzó por no quedarse anclada a la adversidad de una familia humilde, que soñó para su futuro una vida mejor de crecimiento personal y de contribución al progreso y al desarrollo de su país. Elsa supo aprovechar las oportunidades que se le brindaron y estudió con ganas en la escuela, y aunque deseaba progresar en sus estudios, no sabía si podría continuar, ya que no tenía medios económicos suficientes para acceder a la universidad. Hasta el día que se encontró con la organización de los jesuitas EnxarTxad, la cual, bajo una serie de condiciomos, es imprescindible un gobierno con ganas reales de mejorar y que realice una apuesta y una inversión por la educación.

Apostar por la educación significa diseñar un plan sensato de formación de docentes, crear estructuras físicas estables y valorar las labores de mantenimiento, plantear un modelo educativo abierto
1 El Chad es un país con una cultura en la que la mujer sigue infravalorada y sobre todo en el ámbito rural. En muchas ocasiones tiene que abandonar la escuela para cuidar de su familia o simplemente para sobrevivir. 
nes, pudo becar sus estudios universitarios en ingeniería. Además, gracias a su esfuerzo, sacó una de las primeras plazas de un concurso para trabajar en una petrolera para minimizar los impactos ambientales de la extracción de petróleo en el país, lo que le dio la oportunidad de formarse durante un año en Dubai.

Un caso excepcional, de acuerdo, pero real. Por ello, la solución también pasaría por impulsar más casos reales y excepcionales para convertirlos en corrientes. Es cierto que queda demasiado por hacer, que son circunstancias que nos sobrepasan, que no somos más que una gota en un inmenso océano, como recitó santa Teresa de Calcuta, pero también el mar sería menos si le faltara una gota. También es cierto.

No se trata de centrarse en la inmensidad de tareas y problemas que quedan por resolver, sino en ir marcando un camino para que otros puedan replicar o imitar tu acción. Lo indica con precisión Anxo Pérez, el emprendedor gallego creador de un método revolucionario de aprendizaje de idiomas, en uno de sus 88 Peldaños del Éxito: "El éxito de los que mejoran el mundo no se mide por lo que les queda por resolver, sino por lo que ya han resuelto" (p.118). Es demasiado fácil resignarse y refugiarse en la idea de que la realidad es tan compleja que sobrepasa a una sola persona, pero ¿qué hubiera sido de la India sin Gandhi o sin Teresa de Calcuta? ¿De Sudáfrica sin Nelson Mandela? ¿Del colectivo afroamericano en los Estados Unidos sin Martin Luther King?... Ésta es la idea principal que traigo de la experiencia de cooperación y conocimiento en el Chad: al ser conscien-

HEMOS HABLADO DE

\section{Cooperación; educación para el desarrollo; África; voluntariado internacional; experiencias educativas.}

Este artículo fue solicitado por PADRES Y MAESTROS en mayo de 2017, revisado y aceptado en octubre de 2017.

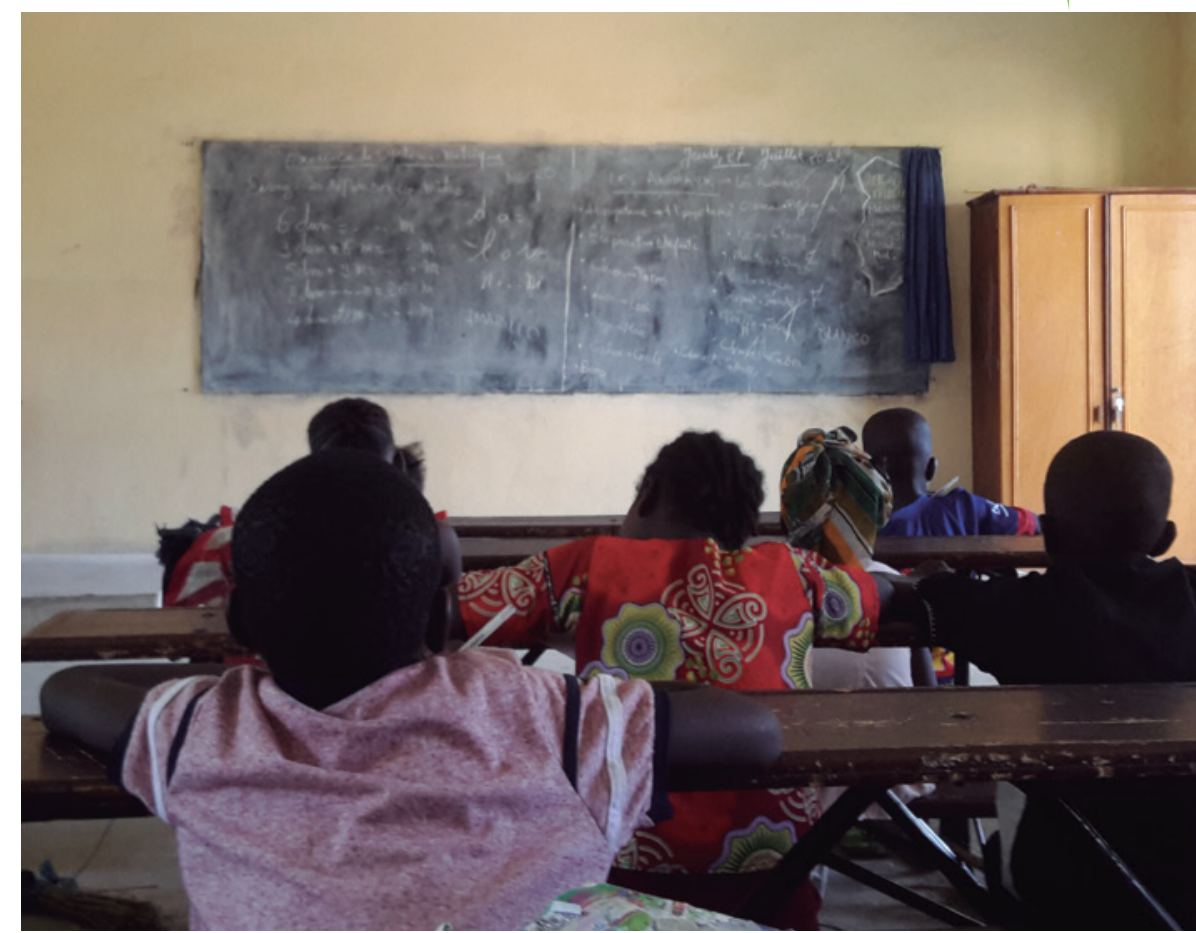

Hay que poner el foco,

no en lo que queda por

solventar, sino en lo que se va

\section{solucionando}

te de la necesidad de mejorar el mundo, es imposible quedarse quieto sin hacer nada y hay que poner el foco, no en lo que queda por solventar, sino en lo que se va solucionando. Porque sí, hay millones de estrellas, la tarea es inabarcable, como narra el relato con el que arranca este artículo, creado por el antropólogo estadounidense Loren Eiseley que usa Anxo Pérez en la citada obra. Pero una estrella que se salve merece la pena •

\section{(D) DRRA SABER MÂS}

Pérez, A. (2014). Los 88 Peldaños del éxito. Barcelona: Alienta.

SAInt-Exupéry, A. (2008). El Principito. Barcelona: Salamandra. 